\title{
POLÍTICAS GLOBAIS E INFLUÊNCIAS NA AGENDA PARA A EDUCAÇÃO/FORMAÇÃO SUPERIOR EM SAÚDE NO BRASIL
}

\author{
GLOBAL POLICIES AND INFLUENCES ON THE HEALTH HIGHER \\ EDUCATION AGENDA IN BRAZIL
}

\author{
Andréa Echeverria Arraes de Alencar ${ }^{1}$ \\ Preciosa Fernandes ${ }^{2}$
}

\begin{abstract}
RESUMO
Focado na problemática da formação superior, o presente artigo tem como objetivo compreender influências de políticas globais em políticas locais para Educação/Formação Superior em saúde no Brasil. Convocam-se contributos de autores que discutem o campo global das políticas educacionais (RAWOLLE \& LINGARD, 2013), da abordagem do ciclo de políticas (BALL \& BOWE, 2001) e de contribuições de Roger Dale (2004) e Thomas Popkewitz (2016). Do ponto de vista metodológico analisam-se relatórios provindos do Banco Mundial, UNESCO e OCDE publicados entre os anos de 2000 e 2018 e legislação no campo da Educação Superior em saúde no Brasil. A análise permitiu constatar que os relatórios contemplam orientações para a formação alinhadas com políticas neoliberais e sintonizadas com o mercado de trabalho. Os resultados apontam ainda para a existência de influências internacionais na agenda da política de Educação Superior no Brasil e nas políticas de Educação em Saúde, em particular.
\end{abstract}

Palavras chave: políticas educacionais; influências internacionais; formação de profissionais de saúde.

\begin{abstract}
Focused on the problematics of Higher Education, this article aims to understand the influences of global policies for education/ higher education training health professionals in Brazil. There are contributions from authors who discuss the global field of educational policies (RAWOLLE \& LINGARD, 2013), the policy cycle approach (BALL \& BOWE, 2001) and contributions from Roger Dale (2004) and Thomas Popkewitz (2016). From a methodological point of view, reports from the World Bank, UNESCO and OECD published between 2000 and 2018 are analysed. The analysis showed that the reports contain training guidelines which are aligned with neoliberal policies and tuned with
\end{abstract}

\footnotetext{
${ }^{1}$ Atualmente é doutoranda pela Faculdade de Psicologia e de Ciências da Educação da Universidade do Porto. Mestra em Saúde Materno Infantil pelo Instituto de Medicina Integral Professor Fernando Figueira. Coordenação do curso de graduação em Psicologia da Faculdade Pernambucana de Saúde. e-mail: andrea.echemartins@gmail.com

${ }^{2}$ Doutora e Mestra em Ciências da Educação pela Universidade do Porto e professora da Faculdade de Psicologia e Ciências da Educação Universidade do Porto. Coordenadora da CAFTe - Currículo, Avaliação, Formação e Tecnologias Educativas. e-mail: preciosa@fpce.up.pt
} 
the labour market. The results also point to the existence of international influences on the agenda of the Higher Education Policy in Brazil and in Health Education policies in particular.

Keywords: educational policies; global influences; training of health professionals.

\section{INTRODUÇÃO}

A velocidade no acesso às informações tem alterado a dinâmica da economia, o conhecimento e a subjetividade dos cidadãos do século XXI. Os valores mudam muito rápido e as formações profissionais estão cada vez mais dependentes dos requisitos do mercado de trabalho. Neste cenário, onde as mudanças se processam em escalas meteóricas, em que a cada dia estamos perante novas demandas para a formação profissional, coloca-se em questão a forma como se aprende, o que mudou e o que permanece válido (APPLE 2005, YOUNG 2010, PACHECO 2014, SANTOS 2017).

Acompanhar essas mudanças no mundo globalizado torna-se, assim, um permanente desafio para a educação e para as Instituições do Ensino Superior (IES), principalmente quando a proposta é oferecer uma formação de qualidade. Importará, pois, que cada IES, e seus responsáveis, se posicionem política e ideologicamente face aos novos desafios e demandas, procurando caminhos inovadores que não deixem a formação prisioneira de uma lógica de mercado.

No quadro destas ideias, o presente artigo analisa orientações de políticas internacionais para o ensino superior preconizadas por organizações internacionais, e suas influências em políticas locais para Educação/Formação Superior em saúde no Brasil. Para isso, foram selecionados documentos provenientes dos organismos internacionais: Banco Mundial (BM), a Organização das Nações Unidas para a Educação, a Ciência e a Cultura (UNESCO) e a Organização para Cooperação e o Desenvolvimento Econômico (OCDE). A escolha destas organizações se justifica pela importância que têm tido na definição de metas e de orientações educacionais, e sua influência a nível local, principalmente a partir do ano 2000, marco no crescimento significativo no Brasil do número de faculdades privadas e o início da construção de leis que legalizam e regulamentam os currículos e o ensino superior em saúde, demarcandose para efeitos de análise, o período de 2000 a 2018. 
No campo específico da Educação Superior no Brasil, foi considerada para análise legislação com foco no campo da saúde.

Assim, num primeiro tópico, explicita-se e problematiza-se a questão da globalização e seu impacto nas políticas locais, notadamente nos currículos para educação do profissional de saúde no século XXI. Apresentam-se os procedimentos metodológicos para, em seguida, nos determos na percepção das influências das políticas globais nas políticas locais e nas propostas curriculares para formação de profissionais de saúde no Brasil.

\section{GLOBALIZAÇÃO E EDUCAÇÃO: QUE INFLUÊNCIAS NAS POLÍTICAS LOCAIS E NO CURRÍCULO?}

Estudos apontam para a necessidade de refletir-se sobre a influência da globalização, do neoliberalismo e das políticas de Estado na educação de forma geral e, em particular no ensino superior (DOLOWITZ, HULME, NELLIS \& O’NEILL, 2000). Segundo Ball (2001), estamos assistindo a um gradual afastamento de políticas de Estado voltadas para os campos social e educativo em detrimento da presença marcante de um novo paradigma de governo educacional, onde predomina o campo econômico e de mercado, numa concepção única de políticas para a competitividade.

Desta forma a análise de textos políticos pode ajudar na compreensão deste contexto de influência macro nas políticas locais. Esta análise é complexa e constitui um dos principais desafios para os pesquisadores do campo da Política Educacional. Ball (2001) afirma que embora não haja uma transposição total da agenda educacional global, as decisões políticas dos Estados Nação vêm sendo tomadas majoritariamente dentro da lógica do mercado global, levando a uma certa “convergência de políticas educativas" (BALL, 2001, p. 112).

Argumenta ainda que há uma tensão básica, no âmago da pesquisa em política educacional entre compromisso com a busca de eficiência e com a busca de justiça social. Nesta linha de pensamento o mesmo autor destaca que as reformas têm sido atravessadas por discursos de excelência, efetividade e qualidade, e por uma lógica e cultura de gerenciamento e de responsabilização (accountability) e de performance (BALL, 2011) que configuram formas de 
agir e pensar dominantes (DALE, 2004) nas novas economias institucionais. Em consequência disto o setor público passa a funcionar como um negócio.

Esta situação tem efeitos no campo da formação, e no modo de se pensar a profissão sendo o profissionalismo substituído por responsabilização, e o coleguismo por competição e por performances (BALL, 2011). É no quadro desta argumentação que se reconhece pertinente o "olhar" que neste ponto se constrói.

Para não cair no erro de realizar uma leitura simplista de influências de documentos de agências multilaterais na legislação e documentos nacionais, segue-se a orientação de Ball (2001) de se trabalhar com o inter-relacionamento das teorias, levando em conta a advertência que faz o autor de manter a coerência nestes estudos.

Nesta perspectiva as decisões educacionais sofrem a interferência de uma linguagem política comum, e a que Ainley (1999) se referiu como sendo uma linguagem política que se traveste de política de aprendizagem, que por sua vez imprime um consenso sobre uma economia baseada no conhecimento. Em concordância, Ball (2001) reconhece que se assiste a um esvaziamento do debate sobre princípios educativos, tendo, nesse debate, vindo a ganhar espaço a discussão sobre o predomínio dos modelos de aprendizagem atreladas as demandas de regulação e gestão relacionados ao desempenho esperado nos rankings avaliativos dos estudantes e das instituição de ensino.

Refletindo sobre influências globais nas políticas locais no Brasil, observa-se que a economia brasileira a partir da década de 1990 foi marcada por profundas mudanças, tais como, o início das privatizações, a entrada de empresas estrangeiras e, de modo mais acentuado, a abertura econômica que buscava iniciar um processo de desenvolvimento baseado na intensificação das relações do país com o mercado externo (STÊNIO \& GARCIA, 2016). Essas transformações na economia brasileira revelaram novas exigências do mercado de trabalho, centralizando a educação como a ferramenta fundamental para maior competitividade e pela difusão dos novos modos de produzir tecnologia.

Ao levantarmos a questão da compreensão de influências de políticas globais em políticas locais para Educação/Formação Superior em saúde no Brasil, entramos, necessariamente, na área do currículo, campo que, em face das alterações econômicas e sociais a que nos referimos, 
e das demandas atribuídas às Instituições Educativas, tem também sido objeto de constantes ressignificações conceptuais.

Segundo Grundy (1887, p.5) "O currículo não é um conceito, mas uma construção cultural. Isto é, não se trata de um conceito abstrato que tenha algum tipo de existência fora e previamente à experiência humana. É antes, um modo de organizar uma série de práticas educativas".

Corroborando esta ideia Lundgren (1981) reconhece que o currículo é o que está por trás de toda a educação, transformando suas metas básicas em estratégias de ensino. Nesta mesma linha também Masetto (2003) argumenta que currículo

[...] é um conjunto de conhecimentos, de saberes, competências, habilidades, experiências, vivências e valores que os alunos precisam adquirir e desenvolver de maneira integrada e explícita mediante práticas e atividades de ensino e de situações de aprendizagem" (MASETTO, 2003, p.67).

Numa leitura de natureza política Popkewitz (2015) sustenta que o currículo pode representar um modelo de tecnologia disciplinadora, visão a que pode ser associada a perspectiva de Sacristán (2017) para quem "o currículo reflete o conflito entre interesses em uma sociedade e os valores dominantes que regem os processos educativos" (SACRISTÁN, 2017, p.17). Para este autor

\footnotetext{
O sistema educativo serve a certos interesses concretos e eles se refletem no currículo. Portanto a prática é um dos eixos vertebrais do pensamento, da pesquisa e dos programas de melhoria para as instituições de ensino. O currículo é um dos conceitos mais potentes, estrategicamente falando, para analisar como a prática se sustenta e se expressa (SACRISTÁN, 2017, p.30).
}

Em O Poder do Simbólico (BOURDIEU, 1989) aponta para o jogo de influências no campo do currículo ao questionar o poder invisível nas relações de comunicação empreendidas pelos agentes formadores na imposição de uma definição de mundo condizente com seus interesses.

Redirecionando a leitura para a problemática em foco neste artigo, na atualidade a demanda de formação do profissional de saúde está voltada para o desenvolvimento de habilidades, atitudes e competências para o trabalho (produção) e, ao mesmo tempo, para a 
intervenção, confrontando o estudante muito cedo com a prática profissional (ZARIFIAN, 2001).

Esta orientação parece estar em linha quer com a proposição de currículo de Masetto (2003), quer com a de Popkewitz (2015) ao considerar que o currículo é proposto como um instrumento de regulação, a partir do seu ordenamento, nas escolhas dos conteúdos, das regras e dos padrões que orientam o processo de aquisição e construção do conhecimento.

Neste raciocínio, faz-se necessário refletir sobre a articulação da cultura local com a teoria e a prática na formação que se pretende oferecer no âmbito da graduação em saúde. Reconhece-se como importante a inclusão de discursos marginais, sem abrir mão da complexidade dos problemas e da diversidade das experiências, das identidades, dos gêneros, dos vários estilos de vida e saberes. Sem desconsiderar as influências globais, faz-se necessário refletir sobre uma formação que incorpore questões relacionadas com problemáticas sociais, humanas contemporâneas, e com o cuidado em saúde no currículo (SANTOS, 2018).

\section{METODOLOGIA DO ESTUDO}

Do ponto de vista metodológico adotou-se a pesquisa bibliográfica e documental de documentos do Banco Mundial (BM), da Organização das Nações Unidas para a Educação, Ciência e Cultura (UNESCO) e da Organização para a Cooperação e Desenvolvimento Econômico (OCDE) e sua relação com leis e diretrizes nacionais.

O critério para a escolha dos documentos foi o período de sua publicação, os anos de 2000 e 2018, e foram incluídos na análise documentos que veiculam orientações para o ensino superior na área da saúde. Justifica-se a seleção deste período em decorrência de crescente aumento, a partir do ano 2000, de instituições de ensino superior privadas no Brasil que acarretou um maior volume de leis que regulamentam o ensino superior e o os currículos na área da saúde.

Considerando que se pretendeu compreender quais as influências de políticas globais em políticas locais para a Educação/Formação Superior em saúde no Brasil, seguiu-se a abordagem do ciclo de políticas (BALL \& BOWE, 1992) contemplando os contextos de influência (análise 


\section{Revista \\ Debates Insubmissos}

das diretrizes internacionais) e de produção de texto (análise de leis e diretrizes de base para Educação superior no Brasil, com foco no campo da saúde).

Assim, num primeiro momento apresenta-se a análise dos documentos selecionados por relação com os diferentes organismos internacionais: BM, UNESCO e OCDE, explicitando as orientações neles preconizadas para a educação/formação superior. Objetiva-se, portanto, delimitar a leitura para orientações que tenham relação com o objeto de estudo, ou seja, a formação superior do profissional de saúde.

Num segundo momento faz-se a análise de influências globais - contexto de influência nas políticas locais para Educação/formação Superior em saúde no Brasil - contexto de produção de texto (BALL \& BOWE, 1992).

\section{RESULTADOS E DISCUSSÕES}

Tendo como base a análise documental de políticas globais e sua influência em políticas locais de Educação para formação do profissional de saúde no Brasil elaborou-se as Tabelas 1 e 2 de modo a facilitar a compreensão sobre quais os documentos internacionais e nacionais que foram objeto de análise. Com base nesta análise, pretende-se compreender como se engendra, no contexto brasileiro (Tabela 2), as interferências de organismos internacionais voltados para o desenvolvimento da educação superior. Dito de outro modo, objetivou-se compreender de que forma as leis que regulamentam a educação têm sofrido influências de uma política contextualizada no sistema econômico internacional sob ditames de organismos, como o BM, a UNESCO e a OCDE. 
Tabela 1. Documentos internacionais que foram objeto de análise.

\begin{tabular}{|c|c|c|}
\hline Organismo & Ano & Título \\
\hline BM & 2000 & La Educacion superior enlos países em desarrollo. Peligros y promessas \\
\hline BM & 2003 & Construir sociedades do conhecimento: nuevos desafios para laeducacion terciária \\
\hline BM & 2011 & Aprendizagem para todos. Estratégia 2020 para a Educação do Grupo Banco Mundial \\
\hline BM & 2017 & Em uma encruzilhada: Ensino Superior na América Latina e Caribe \\
\hline UNESCO & 2000 & Fundamentos da nova educação \\
\hline UNESCO & 2009 & $\begin{array}{l}\text { Conferência Mundial sobre Ensino Superior. As novas Dinâmicas do Ensino Superior e } \\
\text { Pesquisas para a Mudança e o Desenvolvimento Social }\end{array}$ \\
\hline UNESCO & 2012 & $\begin{array}{l}\text { Desafios e perspectivas da educação superior Brasileira para a próxima década } 2011 \text { - } \\
2020\end{array}$ \\
\hline UNESCO & 2015 & Educação para a cidadania global: preparando alunos para os desafios do século XXI \\
\hline UNESCO & 2016 & $\begin{array}{c}\text { Educação 2030: Declaração de Incheon e Marco de Ação para a implementação do } \\
\text { objetivo de desenvolvimento sustentável: assegura a educação inclusiva e equitativa de } \\
\text { aprendizagem ao longo da vida }\end{array}$ \\
\hline OCDE & 2008 & L'enseignement supériur pour la societé de la connaissance \\
\hline OCDE & 2011 & L'ensigmenment superior à l'horizam 2030 \\
\hline OCDE & 2018 & The Future of Education and Skills 2030 \\
\hline
\end{tabular}

Fonte: Quadro construído pela autora com base em documentos consultados em www.worldbank.org, en.unesco.org, www.oecd.or

Tabela 2. Documentos/legislação nacionais que foram objeto de análise.

\begin{tabular}{|c|c|c|}
\hline Documento & Data & Título \\
\hline $\begin{array}{c}\text { PNE } \\
\text { Resolução n. } \\
101.72\end{array}$ & $09 / 01 / 2001$ & Plano Nacional de Educação \\
\hline $\begin{array}{c}\text { SINAES } \\
\text { Lei n. 10.861 }\end{array}$ & $14 / 04 / 2004$ & Sistema Nacional de Avaliação da Educação Superior SINAES \\
\hline $\begin{array}{c}\text { PROUNI } \\
\text { Lei n. 11.096 }\end{array}$ & $13 / 01 / 2005$ & Programa Universidade para Todos \\
\hline $\begin{array}{c}\text { REUNI } \\
\text { Lei n.6.096, } \\
\text { de } 2007\end{array}$ & $24 / 04 / 2007$ & Programa de Apoio a Planos de Reestruturação e Expansão das \\
\hline PNE & $16 / 10 / 2010$ & Universidades Federais \\
Lei n. 8.035 & & Plano Nacional de Educação para o decênio 2011-2020 \\
\hline
\end{tabular}

Fonte: Quadro construído pela autora com base em documentos consultados em portal.mec.gov.br

Os dados a seguir são apresentados por relação com cada um dos organismos e seguindo a ordem apresentada nas Tabelas 1 e 2. 
Revista

Debates Insubmissos

\subsection{Banco Mundial (BM)}

No documento La Educacion superior em los países em desarroll Peligros y promessas. Wasshington: Banco Mundial é reconhecido que se os países em desenvolvimento não investirem em educação superior será cada vez mais difícil beneficiar-se da economia mundial baseada no conhecimento (BM 2000, p.11). É salientado que países em desenvolvimento apresentam inadequada qualificação docente para ensinar, falta de motivação e remuneração insuficiente para os docentes e que, por conseguinte, os estudantes aprendem pouco, devido a um ensino deficiente e a escassa qualidade dos currículos. Preconiza-se, assim, a necessidade de os programas e os currículos das IES promoverem

[...] conhecimento e habilidades especializadas, flexibilidade e inovação permitindo a renovação de estruturas econômicas e sociais, capacidade de readaptar potencialidades e conhecimentos à medida que se produzem as mudanças econômicas e aumentar a quantidade e qualidade das investigações (BM 2000, p. 12).

Esta recomendação está em linha com a ideia também veiculada sobre:

[...] a falta de preparo acadêmico inicial dos estudantes, as limitações de infraestrutura, a tradição cultural que oferece poucas perspectivas laboral para os jovens, a pouca idade na escolha da profissão e a inflexibilidade relacionada a possibilidade de alterar a escolha profissional no início do percurso acadêmico (BM 2000, p.21).

O relatório propõe, então, a inovação do ensino superior nos países em desenvolvimento levando-se em conta a economia do conhecimento, o que demanda instituições novas e muito diferentes das atuais. Sustenta-se que essas novas instituições são mais fáceis de surgir nas economias emergentes do que nas maduras, e reconhece-se que "a nível mundial, as forças do mercado são cruciais no momento de determinar em qual dos temas em competência (...) se concentrará o esforço científico" (p. 90). Neste ponto, a relação entre mercado e educação torna-se estreita, estabelecendo-se um vínculo entre conhecimento, competência, economia e mercado, muito em linha com as perspectivas curriculares antes explicitadas (MASETTO, 2003).

Em harmonia com o discurso veiculado em 2000 pelo BM, no documento do BM (2003), intitulado Construir sociedades del conhecimento: nuevos desafios para la educacion terciária, identificamos, no seu prólogo, a advertência para necessidade de se adotar um enfoque holístico 
mais equilibrado em direção às universidades e de se fomentar um melhoramento do sistema global de educação contínua, empreendendo e apoiando reformas no âmbito da educação terciária.

Descreve-se o compromisso com a educação terciária que contribui para a construção da capacidade de participação dos países em uma economia cada vez mais baseada no conhecimento. Desta forma, aposta-se em políticas alternativas de educação terciária que possam impulsionar o crescimento econômico e a redução da pobreza. E, como forma de reduzir a pobreza, sugere-se, mediante estratégias de redistribuição e empoderamento, estimular a educação superior para oferecer melhores oportunidade e perspectivas de vida a estudantes que pertençam a minorias ou a famílias de baixa renda, contribuindo para melhorar as possibilidades laborais, as perspectivas econômicas e reduzir a desigualdade de acesso (BM, 2003).

Encontra-se, ainda, nestas orientações do BM referências à globalização, à diminuição dos custos com a comunicação e transporte, e à abertura das fronteiras políticas como fatores que, combinados, facilitam a mobilidade do recurso humano capacitado. Esta dinâmica tem produzido, segundo o relatório, um mercado global de capital humano onde os indivíduos têm maiores possibilidade de participar deste modelo de formação.

No que respeita à educação, é sugerido no mesmo documento que, uma educação de melhor nível cultural, mais completa e gratificante, deva preparar pessoas para dirigir uma sociedade moderna e que desta forma possa contribuir para o seu progresso. Propõe-se ainda a criação de um fórum em que a sociedade possa analisar seus problemas e encontrar suas próprias soluções, e por último, oferecer um ambiente adequado ao estudo e ao desenvolvimento da cultura e valores da sociedade. Recomenda-se, ainda, uma educação geral e humanista sustentada por um currículo orientado para conferir conhecimentos abrangentes e desenvolver atitudes intelectuais gerais, numa lógica de desenvolvimento integral das pessoas, diferente de um currículo profissional técnico.

No documento do BM (2011) intitulado "Aprendizagem para Todos - Investir nos Conhecimentos e Competências das Pessoas para promover o Desenvolvimento, Estratégia 2020 para a Educação", identifica-se uma mudança na concepção de educação alinhada com princípios neoliberais, e com o mercado de trabalho. A propósito, postula-se o desenvolvimento de uma educação que vise a competitividade, força de trabalho mais capacitadas, avanços 


\section{Revista \\ Debates Insubmissos}

tecnológicos, e que promovam uma aprendizagem acelerada e formação de jovens com competências corretas para o mercado de trabalho.

A proposta do BM (2011) de promover reformas na educação nos países de renda média ${ }^{3}$ tem como objetivo geral criar uma base global de conhecimento suficientemente forte para liderar essas reformas, assim como, de corresponder ao desejo destas nações de aumentar a competitividade mediante a criação de novas forças de trabalho capacitadas e ágeis. Estas orientações, influenciadas pelas alterações tecnológicas, demarcam um perfil particular dos empregos requeridos pelo mercado de trabalho, e que prioriza uma aprendizagem acelerada e uma melhor gestão dos sistemas de educação.

O BM (2011) tem investido em processos de avaliação de impacto dos programas implantados, reconhecendo, a partir dos resultados dessas avaliações, o papel crescente que o setor privado tem desempenhado na educação superior. Fica latente neste relatório a importância do BM acompanhar e monitorizar esses resultados, realizando análises detalhadas do sistema e do investimento em conhecimentos e em dados que permitam ao Banco e aos decisores políticos analisar ao nível global e agir no nível local (BM, 2011).

No relatório de 2017, intitulado "Em uma encruzilhada: ensino superior na América Latina e Caribe", o ensino superior é objeto de análise. Na introdução é referido que a ampliação do ensino superior, iniciada no ano 2000, criou um panorama novo e complexo, impulsionado pelo crescimento econômico, a abundância fiscal e a ascensão da classe média na América Latina e no Caribe. A conjunção destes fatores possibilitou um aumento de acesso ao ensino superior entre os anos 2000 a 2013, prioritariamente de alunos médios, de família de baixa renda e com menos preparo acadêmico. Este fator veio acarretar o aumento de mercado das IES particulares que atraem alunos de renda mais baixa que os que vão para as IES públicas (BM, 2017). Há, portanto, “uma expansão de IES particulares e não universitárias que conquistam uma maior fatia do mercado" (p.20). Como forma de resolução desta encruzilhada é proposto pelo BM (2017) "o incentivo, a concorrência, a opção, o monitoramento e a informação como

\footnotetext{
${ }^{3} \mathrm{~A}$ renda média domiciliar per capita representa a soma dos rendimentos mensais dos moradores do domicílio, em reais, dividida pelo número de seus moradores. Fonte: ibge.gov.br .
} 
mecanismos para o desempenho de um papel importante no movimento de superação da atual encruzilhada" (p.26). Em face desta situação, é enunciado no relatório em análise, que um novo perfil de aluno vai surgir, bem como uma nova oferta de ensino superior.

Estabelecendo uma articulação entre as orientações do BM $(2000,2003,2011,2017)$ e a legislação no campo da Educação Superior, publicada no Brasil (Lei n ${ }^{\circ} 101.72 / 2001$; Lei $n^{\circ}$ 10.861/2004) identificam-se pontes e influências, das quais se destacam:

a) Na Lei n ${ }^{o} 101.72 / 2001$ do PNE, no Capítulo IV intitulado Da Educação Superior, se determina a inclusão nas diretrizes curriculares dos cursos de formação docente de temas relacionados às problemáticas de: gênero, educação sexual, ética (justiça, diálogo, respeito mútuo, solidariedade e tolerância), pluralidade cultural, meio ambiente, saúde e temas locais. Desta forma observa-se, neste ponto, estreita relação entre diretrizes preconizadas no relatório do BM (2003), nomeadamente no que diz respeito à educação voltada para humanização com enfoque em temas ambientais e voltados para a formação generalista.

b) Com a Lei $n^{\circ} 10.861 / 2004$, a relação de influência torna-se clara na proposta de que as metas educacionais sejam monitoradas pelo Sistema Nacional de Avaliação da Educação Superior (Sinaes), que é formado por três componentes principais: a avaliação das instituições, dos cursos e do desempenho dos estudantes. A avaliação deve girar em torno principalmente: o ensino, a pesquisa, a extensão, a responsabilidade social, o desempenho dos estudantes, a gestão da instituição, corpo docente e instalações.

c) A Lei $n^{\circ}$ 8.035/2010 institui o Plano Nacional de Educação (PNE) para o decênio 20112020, com vigência de dez anos. Encontra-se, por consequência, a recomendação, através de metas e estratégias, da necessidade de melhoria do ensino superior, com incentivo à promoção humanista, científica, cultural e tecnológica com padrão de qualidade e equidade, revelando ainda influências de orientações preconizadas no relatório do BM (2003).

Desse modo, cabe às IES fomentar estudos e pesquisas que analisem a necessidade de articulação entre formação, currículos, pesquisa e o mundo do trabalho, considerando as necessidades econômicas, sociais e culturais. Observa-se, por conseguinte, influências nas 
políticas locais com a proposta de instituir-se o permanente monitoramento, que por sua vez, direciona para ações de avaliação, regulação e supervisão, assim como de autoavaliação institucional. Essas diretrizes estão incorporadas nas leis e resoluções que constituem o corpus legal de controle do MEC para a educação superior no Brasil.

Em síntese, a leitura e análise dos documentos internacionais e a sua relação com as leis promulgadas no período estudado apontam para uma relação entre a demanda de uma formação superior atrelada às necessidades de melhoria e qualidade (Lei $\mathrm{n}^{\circ} 101.72 / 2001$ ), e ao mesmo tempo, para um vínculo entre educação e o mercado de trabalho (Lei $n^{\circ}$ 8.035/2010). Desta forma é importante ressaltar que o estímulo, a partir da influência da orientação internacional na política educativa no Brasil, ao acesso ao ensino superior da população menos favorecida financeira e culturalmente, estimulou à livre iniciativa para o crescimento do ensino privado.

\subsection{Organização das Nações Unidas para a Educação, Ciência e Cultura - UNESCO}

No que diz respeito à UNESCO, conforme Tabela 1, foram identificados quatro documentos que analisaremos a seguir.

Em nota introdutória do relatório Fundamentos da nova educação (UNESCO 2000), são referenciados os quatro pilares do Relatório Delors et al (1996) e os Sete Saberes pensados por Morin (1999). Lê-se que levar em consideração estes preceitos tornou-se imprescindível para que o século XXI avance em direção à universalização da cidadania (UNESCO 2000).

Neste documento é dado um enfoque sobre o papel do Estado no financiamento, a autonomia e liberdade das universidades. A recomendação incide na proposta de se pensar em um sistema

[...] híbrido de financiamento público/privado, e a orientação do controle e supervisão pelo Estado dos gastos, da avaliação, da qualidade acadêmica e da divulgação de desempenho, ficando está a cargo da publicidade, fortalecendo assim o caráter de mercado do ensino superior (UNESCO, 2000, p.6).

Identifica-se, pois, um grande incentivo às instituições educativas a se atrelar as propostas educativas ao mercado, pressionando as universidades a produzirem inovação requeridas pelas necessidades de competitividade da economia capitalista (UNESCO, 2000).

Uma consequência destas orientações é a separação, em polos opostos de prioridades: por 


\section{Revista \\ Debates Insubmissos}

um lado os que vão estar no polo de excelência - voltado para as pesquisas de ponta, e seu direcionamento para as elites, e no polo oposto - a proliferação de instituições de ensino superior privadas voltadas para a qualificação profissional, indicada para os que até então estavam excluídos do acesso ao ensino superior e o seu direcionamento para o trabalho.

No relatório da Conferência Mundial sobre Ensino Superior: As novas Dinâmicas do Ensino Superior e Pesquisas para a Mudança e o Desenvolvimento Social (UNESCO 2009), identifica-se uma aposta no direcionamento de ações educativas que fortaleçam a formação superior, ancorada na ciência e na cultura. São reforçadas ações de desenvolvimento da educação superior, a partir das seguintes diretrizes: a responsabilidade social da educação superior, acesso, equidade e qualidade, internacionalização, regionalização, mundialização, aprendizagem, investigação e a inovação (UNESCO, 2009).

Dentre a responsabilidade social da educação superior o relatório reforça o papel social do ensino superior como um bem público, que deve estar preparado para dar respostas diante da complexidade e dos desafios mundiais, presentes e futuros.

Para tanto, os saberes devem estar ancorados na investigação, no ensino e no serviço à comunidade, com autonomia e liberdade acadêmica, devendo estar centrado em aspectos interdisciplinares e na promoção de pensamento crítico e da cidadania ativa, contribuindo para o desenvolvimento sustentável, a paz, e o bem-estar. As orientações contidas neste documento objetivam priorizar os direitos humanos, entre eles a igualdade de gênero, a inclusão e o acesso a população desfavorecida economicamente e a qualidade no ensino (UNESCO, 2009).

A partir destas orientações, segundo o relatório, busca-se proporcionar competências sólidas para formar cidadãos éticos e comprometidos com a paz, os direitos humanos e os valores da democracia, estimulando o acesso à informação, a transparência e a abertura de todo estabelecimento de ensino (UNESCO, 2009).

O documento Desafios e Perspectivas da Educação Superior Brasileira para a Próxima Década 2011-2020 (UNESCO 2012) lança os seguintes desafios:

I) a democratização do acesso ao ensino superior e da permanência; II) a ampliação da rede pública superior e de vagas nas IES públicas; III) a redução das desigualdades regionais, quanto ao acesso e à permanência; IV) a formação com qualidade; V) a diversificação da oferta de cursos e dos níveis de formação; VI) a qualificação dos 


\section{neyste

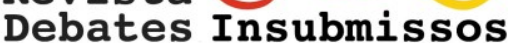

profissionais docentes; VII) a garantia de financiamento, especialmente para o setor público; VIII) a relevância social dos programas oferecidos; e IX) o estímulo à pesquisa científica e tecnológica"(UNESCO, 2011-2020 p.16).

Também foram discutidas nesse documento as perspectivas abertas pela internacionalização, pela regionalização e pela mundialização, bem como pelas diferentes formas de utilização das novas tecnologias da informação e da comunicação. Estas orientações reforçam a necessidade de estímulo e investimento em novas formas de aprendizagem, de gestão e aplicação de conhecimento. Refere-se ainda a preocupação frente à expansão do setor privado e a redução das desigualdades regionais (UNESCO, 2011-2020)

No relatório intitulado Educação para a cidadania Global: preparando alunos para os desafios do século XXI (UNESCO, 2015), encontra-se a constatação de uma:

[...] mudança no discurso e na prática da educação. Essa mudança reconhece a relevância da educação e da aprendizagem para entender e resolver questões globais nas áreas social, política, cultural, econômica e ambiental. O papel da educação tem ido além do desenvolvimento de conhecimento e habilidades cognitivas para a construção de valores, soft skills e atitudes entre alunos. Espera-se que a educação facilite a cooperação internacional e promova a transformação social de uma forma inovadora em direção a um mundo mais justo, pacífico, tolerante, inclusivo, seguro e sustentável (UNESCO, 2015, p. 10).

Para dar conta desta mudança o relatório reforça a necessidade de se instituir uma pedagogia transformadora que seja capaz de capacitar os estudantes para a solução de desafios que envolvem toda a humanidade, relacionados ao desenvolvimento sustentável e à paz. Como é enunciado, esses desafios

[...] incluem conflitos, pobreza, mudança climática, segurança energética, desigualdade na distribuição populacional, e todas as formas de desigualdade e injustiça que ressaltam a necessidade de cooperação e colaboração entre os países (Educação para a cidadania Global: preparando alunos para os desafios do século XXI (UNESCO 2015 p.11).

Neste raciocínio, é sustentado que Educação para uma cidadania global deve

(i) estimular alunos a analisar criticamente questões da vida real e a identificar possíveis soluções de forma criativa e inovadora, (ii) apoiar alunos a reexaminar pressupostos, visões de mundo e relações de poder em discursos "oficiais" e considerar pessoas e grupos sistematicamente sub-representados ou marginalizados (iii) enfocar o engajamento em ações individuais e coletivas, a fim de promover as mudanças desejadas; e (iv) envolver múltiplas partes interessadas, incluindo aquelas que estão fora do ambiente de aprendizagem, na comunidade e na sociedade mais ampla" (UNESCO, 2015, p.14). 


\section{Revista \\ Debates Insubmissos}

No último documento analisado Educação 2030: Declaração de Incheon e Marco de Ação para a implementação do objetivo de desenvolvimento sustentável: assegura a educação inclusiva e equitativa de aprendizagem ao longo da vida (UNESCO, 2016), as orientações reforçam as medidas para a melhoria da qualidade da aprendizagem com o desenvolvimento de atitudes, valores, aptidões, competências e conhecimentos que permitam aos cidadãos conduzirem suas vidas de forma plena e com capacidade de tomar decisões fundamentadas. Para tanto, é preconizada a necessidade de se garantir o acesso à educação superior a toda a população, desenvolvendo competências para o trabalho, com pensamento crítico, criativo e com o perfil de liderança para enfrentar as incertezas do futuro.

Outra tendência apontada neste relatório é o estímulo à mobilidade do corpo docente e dos estudantes para a melhoria de sua formação acadêmica reforçando a competitividade mundial. Deve-se, portanto, conforme é enunciado, "estimular o uso da tecnologia, dos recursos educativos de livre acesso, e da educação à distância, criando oportunidades equitativas de acesso a população de idade avançada, prestando particular atenção aos grupos vulneráveis" (UNESCO, 2016).

Parece poder inferir-se da análise que orientações preconizadas neste relatório reforçam a necessidade de se traçar políticas intersetoriais que promovam o desenvolvimento de competências profissionais, fortalecendo o vínculo entre a ciência e sua aplicação nos variados contextos, para que possam criar alianças eficazes entre os setores públicos e privados.

Em face da análise feita aos cinco documentos da UNESCO e à semelhaça da relação que também estabelecemos entre os relatórios do BM e a legislação em educação publicada no Brasil, fazemos agora também uma leitura articulada entre orientações preconizadas nos documentos acima citados da UNESCO (2000, 2009, 2012, 2015 e 2016) e a legislação identificada. Assim,

a) O Sistema Nacional de Avaliação da Educação Superior (SINAES), por meio da Lei $\mathrm{n}^{\mathrm{o}} 10.861 / 2004$ formaliza o compromisso das IES com a qualidade do ensino superior e com a orientação da expansão de oferta, aumento de eficácia institucional e efetividade acadêmica e social, bem como a promoção do compromisso e responsabilidade social. Estas determinações estão em sintonia com orientações 


\section{Debates Insubmissos}

Revista

internacionais (UNESCO, 2000, 2009, 2012). Desta forma, reforça a demanda de controle através do monitoramento de desempenho com foco em três componentes principais: a avaliação das instituições, dos cursos, e do desempenho dos estudantes, considerando o ensino, a pesquisa, a extensão, a responsabilidade social, o desempenho dos alunos, a gestão da instituição, o corpo docente e as instalações. Para estas avaliações MEC exige que as IES sigam uma série de instrumentos complementares, que, em sintonia com os documentos analisados (UNESCO 2000, 2009, 2012) reforçam a necessidade de autoavalição permanente, com os instrumentos padronizados para avaliação externa como o Exame Nacional de Desempenho dos Estudantes (avaliação dos cursos de graduação e instrumentos de formação (censo e cadastro).

b) A partir da análise das Leis $n^{0} 11.096 / 2005$ e $n^{0}$ 6.096/2007 verifica-se que as orientações internacionais aludidas impactam na implementação de propostas de novos programas para o Ensino Superior que passam a reforçar a necessidade de ampliação de vagas públicas. Com a Lei nº.096, de 24 de Abril de 2007 foi criado o Programa de Apoio a Planos de Restruturação e Expansão das Universidades (REUNI $2007)^{4}$, estimulando a interiorização e o fortalecimento da educação tecnológica e, especialmente, a ampliação de políticas de financiamento estudantil (PROUNI e FIES) ${ }^{5}$. Dentro desta linha de incentivo vale ressaltar o estímulo a modalidade de ensino a distância, políticas de inclusão e de ações afirmativas e por último o compromisso com a formação de professores da educação básica. Desta forma, constata-se a existência de influências entre orientações da UNESCO com as leis

\footnotetext{
${ }^{4}$ O REUNI tem como principal objetivo a expansão física, acadêmica e pedagógica da rede federal de educação superior no Brasil. As ações do programa contemplam o aumento de vagas nos cursos de graduação, a ampliação da oferta de cursos noturnos, a promoção de inovações pedagógicas e o combate à evasão, entre outras metas que têm o propósito de diminuir as desigualdades sociais no país.

${ }^{5}$ O PROUNI - Programa Universidade Para Todos, foi implantado em 2005 pelo Ministério da Educação MEC objetivando ampliar as oportunidades de acesso ao ensino superior no Brasil. O FIES - Fundo de Financiamento Estudantil do Ensino Superior foi criado também pelo MEC em 1999 objetivando atender prioritariamente estudantes de baixa renda que estejam matriculados em IES particular.
} 
nacionais que instituem programas com amplo impacto nos programas e ações das IES (UNESCO, 2012, 2015, 2016).

Reconhece-se, portanto, uma ligação entre as orientações dos relatórios internacionais e as leis e diretrizes para a Educação Superior no Brasil. Em linhas gerais, observa-se uma estreita relação de influências e impacto entre as orientações da UNESCO a partir da década de 2000 e a legislação brasileira, cuja orientação incide na obrigatoriedade de monitoramento, avaliação e controle pelo estado, como também o estimulo à qualidade do ensino e inclusão.

De um outro ponto de vista, não devemos desconsiderar a importância que a UNESCO desempenha de cooperação e ajuda voltada à população mais necessitada do planeta. Estas orientações reforçam a necessidade da inclusão de temas tão caros à humanidade, tais como: cidadania ativa, desenvolvimento sustentável, paz e bem-estar, igualdade de gênero, inclusão, acesso ao ensino da população desfavorecida, direitos humanos, redução da desigualdade, cooperação internacional, etc.

\subsection{Organização para a Cooperação e Desenvolvimento Econômico (OCDE)}

No primeiro documento da OCDE analisado, intitulado O Ensino Superior para a sociedade do conhecimento as orientações relativas ao Ensino Superior reforçam a necessidade de que este contribua para o desenvolvimento econômico dos países, priorizando a formação do capital humano; a constituição de bases de conhecimento; a difusão e a valorização do conhecimento produzido por meio das pesquisas; a manutenção dos conhecimentos e a sua transmissão inter geracional (OCDE, 2008).

O documento L'enseignementsupérieur à l'horizont 2030 (OCDE 2011), ao fazer referência ao Processo de Bolonha ${ }^{6}$, preconiza que deve-se priorizar o estímulo à mobilidade internacional dos estudantes e dos professores para a troca universitária e cultural entre os povos, principalmente da comunidade europeia, e ainda, a necessidade de ter uma população

\footnotetext{
${ }^{5}$ Em 19 de junho de 1999, na cidade italiana de Bolonha, ministros da educação de 29 países europeus assinaram a Declaração de Bolonha, documento que prevê a livre mobilidade dos estudantes (europeus ou não) entre as universidades européias mediante a criação do Espaço Europeu do Ensino Superior. O principal objetivo da criação do Espaço Europeu do Ensino Superior é o aumento da competitividade do próprio Sistema.
} 
ativa mais bem educada em uma economia emergente ou que está envelhecendo (OCDE 2011).

Neste contexto de influências das políticas internacionais, a OCDE, no relatório de abril de 2018, intitulado The Future of Educationand Skills 2030, lança questões e desafios para os governos, visando a promoção de políticas globais relacionadas especificamente com o campo do currículo e com a formação dos futuros profissionais, interrogando-se:

- Que conhecimentos, habilidades, atitudes e valores os estudantes de hoje precisam para prosperar e moldar seu mundo?

- Como os sistemas institucionais podem desenvolver esses conhecimentos, habilidades, atitudes e valores de forma eficaz?

As preocupações apontadas no relatório parecem direcionar-se para a necessidade de, por um lado, se traçarem objetivos mais amplos para a educação, priorizando o bem-estar individual e coletivo e, por outro, se pensar os currículos de formação numa perspectiva mais ampla, organizando-os não apenas para a obtenção de conhecimentos, mas também para o desenvolvimento de habilidades, atitudes e valores. Dá-se clara ênfase ao desenvolvimento de competências para transformar a sociedade, e à construção de projetos inovadores que permitam avançar em direção a uma mudança ecossistêmica (OCDE, 2018).

É neste contexto de orientações das políticas internacionais (OCDE, 2018) que vamos encontrar a ênfase na implantação do currículo do futuro que deve ser projetado envolvendo os estudantes para motivá-los, e reconhecendo os seus conhecimentos, habilidades, atitudes e valores. Um ensino que seja desafiador para os participantes envolvidos, alinhado com os processos de avaliação, e com uma adequação do conhecimento a situações problemas, que permita o desenvolvimento, nos estudantes, de um pensamento e reflexão profundos, capazes de garantir a qualidade da sua formação. Preconiza-se, nestes pressupostos, que o estudante possa, de modo bem informado, fazer as suas escolhas (OCDE, 2018).

O relatório reforça ainda que o futuro da educação e das habilidades 2030 também passa por um trabalho de redesenho e de implementação de currículos para enfrentar os desafios do século XXI). O incentivo será de, a partir da análise de currículos internacionais, os países 
participantes da OCDE possam refletir sobre suas próprias práticas e aprender com as experiências de outros (OCDE, 2018).

Desta forma o relatório acima citado propõe, para a reformulação dos currículos, seis questões políticas comuns, a que importa prestar atenção:

1. Sobrecarga curricular;

2. Gerenciamento do intervalo de tempo entre o currículo atual e as necessidades futuras;

3. Garantir a equidade por meio de inovações curriculares;

4. Gerenciando a flexibilidade e autonomia do currículo;

5. Incorporar valores no currículo;

6. Projeto / planejamento para implementação eficaz.

A partir destas recomendações dos relatórios analisados (OCDE 2008, 2011, 2018), identificamos um direcionamento para que os países repensem a qualidade do ensino, avaliando a relevância, efetividade e eficiência dos procedimentos para a sua melhoria. As orientações passam de indicação de caminhos para recomendações incisivas e pontuais.

Segundo Robertson \& Dale (2017) a OCDE - após a criação de uma Direção separada para educação em 2002 - e a partir da análise destas influências globais nas políticas locais, cria um vocabulário ideológico da reforma, que se seguiu ao sucesso da política neoliberal nos EUA e no Reino Unido em particular. Ou seja, estas orientações se apoiam em um modelo distante das realidades e características dos sistemas dos países periféricos como o Brasil.

$\mathrm{Na}$ linha de raciocínio que estamos seguindo neste artigo, intenta-se, uma vez mais, identificar influências destas orientações internacionais na legislação implementada no Brasil (contexto de produção de texto), que passamos a referenciar:

a) Observa-se na Lei $n^{\mathbf{o}} 10.861 / 2004$, com a instituição do Sistema de Avaliação da Educação Superior (SINAES), a exigência de ranqueamento e classificação das universidades, assim como o caráter punitivo das políticas de avaliação, a partir de um modelo standard que se deve seguir. Portanto, adotar um sistema parecido de avaliação 
entre vários países de diferentes contextos, com realidades díspares reflete uma imposição que vem de cima e parece não respeitar as diferenças entre os povos.

b) Ao analisarmos a Lei $n^{\circ} 8.035 / 2010$ que institui metas e estratégias, especificamente referentes a educação superior para o decênio 2011-2020, juntamente com as Leis $\mathrm{n}^{\circ}$ $10.861 / 2004, \mathrm{n}^{\mathrm{o}} 11.096 / 2005$ e $\mathrm{n}^{\mathrm{o}} 6.096 / 2007$ traça-se um panorama de entrelaçamento entre as orientações dos organismos internacionais com relação ao processo de mercantilização da educação superior no Brasil, iniciado no período do ano 2000, precisamente nos relatórios da $\operatorname{OCDE}(2008,2011)$. Cria-se um arcabouço político e jurídico que busca viabilizar a privatização da educação superior atendendo entre outras a demanda de inclusão da população com dificuldade de acesso ao ensino superior. Nesta mesma lei observa-se influências na legislação sobre avaliação como é o caso das Leis $n^{\circ} 8.035 / 2010$ e lei $n^{\circ} 103$ de 2012. Estas enfocam a necessidade de melhoria da qualidade, monitoramento, avaliação de desempenho dos estudantes e o fomento à estudos e pesquisas que analisem a necessidade de articulação entre formação, currículo, pesquisa e o mundo do trabalho, considerando a necessidade econômica, sociais e culturais.

Em síntese, segundo Robertson \& Dale (2017), as orientações da OCDE passam a enfatizar a necessidade de limitar a intervenção do governo e embasar a governança sobre o que era conhecido como New Public Management (Nova Gestão Pública). Esta tendência, na perspectiva dos autores, vem reforçar a ideia de:

[...] que os estados deveriam ser governados tanto quanto possível com base em princípios de mercado; crescente expertise técnica em monitoramento (assumindo o lugar da lógica anterior de revisão por pares); e uma ênfase crescente na quantificação para elaborar a política educacional por meio do projeto INES [Indicadores de Sistemas Educacionais] (ROBERTSON\& DALE, 2017, p. 127).

Os autores alertam ainda para o fato de que estas orientações representam uma lógica comum de desconfiança da política e da necessidade de fornecer informações precisas para a organização não apenas da economia, mas de todo o campo da administração pública. 


\section{CONSIDERAÇÕES FINAIS}

Com o presente artigo objetivou-se compreender influências de políticas globais em políticas locais para Educação/Formação Superior no Brasil. Para tanto analisaram-se orientações internacionais enunciadas em relatórios do BM, UNESCO e OCDE, publicados entre os anos de 2000 à 2018, e sua influência nas políticas brasileiras orientadas para a Educação/ formação de profissionais em saúde.

Ao se fazer esta relação entre o contexto de influência global para o contexto local (BALL, 1996) compreendemos, em acordo com António Teodoro (2003), que, de fato, aqueles organismos internacionais:

[...] desempenham um decisivo papel na normalização das políticas educativas nacionais, estabelecendo uma agenda que fixa não apenas prioridades mas igualmente as formas como os problemas se colocam e equacionam, constituindo uma forma de fixação de um mandato, mais ou menos explícito conforme a centralização dos países (TEODORO, 2003, p. 33).

Com efeito, a análise realizada aos diferentes documentos permitiu identificar três principais eixos de influência das organizações internacionais nas políticas locais para educação superior em saúde no Brasil: políticas públicas-privadas; avaliação e monitoramento; inclusão/equidade e responsabilidade social; e valores.

No que concerne ao primeiro eixo, observa-se um alinhamento das políticas para Educação Superior em saúde no Brasil com a ideologia do neoliberalismo subordinando a Educação à lógica do mercado, demarcando políticas de avaliação, monitoramento e de resultados atreladas ao desenvolvimento econômico (BM, UNESCO E OCDE). Identifica-se, igualmente, um direcionamento para a qualidade do ensino, avaliando a relevância, efetividade e eficiência dos procedimentos para a sua melhoria (BM, UNESCO, OCDE).

Observam-se, também, influências relacionadas com demandas de inclusão/equidade e responsabilidade social (UNESCO), em propostas de formação orientadas para a inovação, sustentabilidade e flexibilidade curricular (Leis $n^{\circ} 8.035 / 2010$ e lei $n^{\circ} 103$ de 2012). Neste domínio, a análise permitiu ainda constatar como influência de um discurso orientado para inclusão e equidade, o alargamento de vagas públicas no ensino superior, bem como a ampliação de políticas de financiamento estudantil e o estímulo ao ensino a distância (UNESCO). 
Com relação aos valores, os discursos remetem para uma atenção ao pluralismo cultural, (BM) que se reflete em propostas curriculares de formação docente orientadas para problemáticas voltadas para a humanização e atenção à diversidade (Leis no 11.096/2005 e n ${ }^{\circ}$ 6.096/2007). De um outro ângulo, a análise permitiu também compreender influências direcionadas para o desenvolvimento, nos estudantes, de habilidades, atitudes, competências e valores que induzem a se pensar na promoção de capital humano para se trabalhar novos modelos de ensino-aprendizagem (OCDE).

Neste sentido parece inferir-se uma certa tendência de substituição de uma visão da Educação na sua compreensão ampla de formação humana, orientada para a transformação social e para a formação humana que deve levar em conta os valores éticos, morais e de responsabilidade, por um modelo de natureza mais tecnicista, que visa unicamente acompanhar e adequar a formação ao mundo competitivo do mercado (desenvolvimento econômico).

Os eixos de influência identificados, e as nuances que abarcam, configuram três grandes desafios para a formação de profissionais de saúde no Brasil. Um primeiro desafio tem a ver com o reconhecimento de que essas propostas de formação tenderão a sintonizar-se com políticas neoliberais (agenda global), o que significará alinharem-se pelas demandas do mercado de trabalho e empregabilidade. Um segundo desafio, articulado com o primeiro, prende-se com o perfil do profissional de saúde voltado para uma atenção integral das pessoas, famílias, grupos sociais e comunidades. Este desafio requer, por seu lado, que as IES trabalhem segundo lógicas de aproximação entre serviços de saúde (SUS), o contexto local e as instâncias formadoras de profissionais de nível superior (agenda local).

Um terceiro desafio, que pode ser relacionado com este último aspecto, tem como foco a importância da gestão e desenvolvimento da qualidade (agenda global), conduzida a partir da avaliação, monitoramento e desempenho institucional.

Conclui-se, assim, que o contexto de produção de texto que normatiza a Educação Superior no Brasil, e as políticas de formação em saúde, indica um alusivo enlace com a política global voltada, quer a interesses econômicos e de mercado, e com enfoque na qualidade, quer a pressupostos de natureza inclusiva, com preocupações com a equidade e responsabilidade social. Esta, é, pois, uma relação tensional que requer das Instituições do Ensino Superior, com 
responsabilidades na formação de profissionais de Saúde, maior atenção tendo em conta um perfil profissional direcionado, simultaneamente, para a interprofissionalidade e o trabalho interdisciplinar, e para uma ação comunitária de atenção às pessoas, famílias e grupos sociais.

Em síntese, o estudo não teve a pretensão de esgotar a leitura das influências das políticas globais na produção de políticas locais de Educação/Formação Superior em saúde no Brasil. Enquanto estudo historicamente situado, representa um ponto de partida para aprofundamentos futuros.

\section{REFERÊNCIAS}

APPLE, Michel W. Para além da lógica do mercado: compreendendo e opondo-se ao neoliberalismo. Rio de Janeiro: DP\&A Editora, 2005.

BALL, Stepfen J. Educação global S.A: novas redes políticas e o imaginário neoliberal. Ponta Grossa: Ed. Unimep, 2014.

BALL, Stepfen J. Diretrizes Políticas Globais e Relações Políticas locais em educação.

Currículo sem Fronteiras, v. 1, n.2, p. 99-116, jul/dez 2001.

BANCO MUNDIAL La enseñanza superior: Las lecciones derivadas de la experiência. Washington, D.C,1995.

BOURDIEU, Pierre. O Poder Simbólico. Rio de Janeiro: Editora Bertrand,1989.

BORGES, Maria Alice Guimarães. A compreensão da sociedade da informação. Ciência da informação. Ibict, v. 29. N. 3, 2000.

BORGES, Maria Alice Guimarães. A Unesco e o direito à educação superior. In: Congresso Ibero-americano de política e administração da educação, São Paulo, v.2, p.1-15, 2011. BRASIL. Lei no 10.172, de 09 de Janeiro de 2001. Aprova o Plano Nacional de Educação e dá outras providências. Diário Oficial União: Seção1: Brasília, DF, p., 10 jan.2001 Disponível em: http://portal. mec.gov.br/arquivos/pdf/L10172.pdf. Acesso em: 15 jun. 2018. 
BRASIL. Lei no 10.861, de 14 de Abril de 2004. Institui o Sistema Nacional de Avaliação da Educação Superior -SINAES e dá outras providências. Diário Oficial União: Seção 1, Brasília, DF, p.3-4, 15 abr. 2004. Disponível em: http://portal.mec.gov.br/arquivos/pdf/ 110861.pdf . Acesso em: 15 jun.2018.

BRASIL. Decreto no 5773, de 9 de maio de 2006. Dispõe sobre o exercício das funções de regulação, supervisão e avaliação de instituições de educação superior e cursos superiores de graduação e sequenciais no sistema federal de ensino. Diário Oficial União: Seção 1, Brasília, DF, p.6-10, 10, maio 2006. 10 maio 2006. Disponível em: http://portal.mec.gov.br/setec/arquivos/pdf/dec_5773_06.pdf. Acesso em: 15 jun. 208 DALE, Roger. Globalização e educação: demonstrando a existência de uma “cultura educacional mundial comum" ou localizando uma "agenda globalmente estruturada para a educação”. Educ. Soc. Campina, São Paulo, v. 25, n. 87, p. 423-460 maio/agost. 2004. GENTILI, Pablo A. A.; SILVA, Tomaz Tadeu. Neoliberalismo, qualidade total e educação. 15 ed. Petrópolis, RJ: Vozes, 2015.

GENTILI, Pablo A. A.; SILVA, Tomaz Tadeu. A universidade na penumbra: o círculo vicioso da precariedade e a privatização do espaço público. São Paulo: Cortez, 2001.

GENTILI, Pablo A. A.; SILVA, Tomaz Tadeu. Pedagogia da exclusão: crítica ao neoliberalismo em educação. Editora Vozes, 19 ed. Petrópolis, RJ, 2018.

LUCHESI, Martha Abrahão Saad. Políticas para a educação superior no Brasil no contexto sul-americano: convergências e transformações na passagem do século. Revista Brasileira de Política e Administração da Educação. v.23, n.3, p. 513-528, set./dez. 2007.

MACEDO, Roberto Sidnei. Currículo: campo, conceito e pesquisa. Petrópolis, Rio de Janeiro: Editora Vozes, 2007.

MAUÉS, Olgaíses Cabral; SOUZA, Michele Borges. Internacionalização da educação via ciências sem Fronteiras. In: SEMINÁRIO NACIONAL DA REDE UNIVERSITAS/BR: Direito à educação superior pública no contexto da crise brasileira, 25, Brasília, Anais, Brasília: UNIVERSITAS/Br. Universidade de Brasília, 2017. 
MACEDO, Elizabeth. Currículo: Política, Cultura e Poder. Currículo sem fronteiras. Rio de Janeiro: Universidade do Estado do Rio de Janeiro, v.6, n.2 p.98-113, jul/dez. 2006.

MASETTO, Marcos Tarcísio. Competência Pedagógica do Professor Universitário, São Paulo: Summus Editora, 2003.

MATURAMA, Roberto. H.: VAREL G. F. A árvore de Conhecimento: as bases biológicas do entendimento humano. São Paulo: Editora Psy, 1995.

MATURAMA, Roberto. H.: VAREL G. F. Emoções e linguagem na educação e na política. Belo Horizonte: UFMG: 1998.

MATURAMA, Roberto. H.: VAREL G. F. Cognição, ciência e vida cotidiana. Belo Horizonte, UFMG, 2001.

MATURAMA, Roberto. H.: VAREL G. F. Formação Humana e Capacitação. Petrópolis: Editora Vozes, 2000.

MELO, Carolina de Castro Barbosa; ALVES, Renato Oliveira: Lemos, Stela Maris Aguiar. Metodologias de ensino e formação na área de saúde: revisão da literatura. Revista CEFAC, 16(6), 2015-2028, 2014.

MOTA William Pessoa. O Banco Mundial e a contrarreforma da educação superior brasileira, no Governo Lula da Silva (2003-2010). Tese (Doutorado em Educação) Programa de Pós-Graduação em Educação, Universidade Federal do Pará, Belém, 2016. ORGANIZAÇÃO DE COOPERAÇÃO E DESENVOLVIMENTO ECONÔMICO (OCDE). Enseignement supérieur pour la société de la connaissance, 2008. Disponível em:<http://ifgu.auf.org/ media/document/40345193.pdf $>$.

ORGANIZAÇÃO DE COOPERAÇÃO E DESENVOLVIMENTO ECONÔMICO (OCDE). L'enseignement supérieur à l'horizon 2030. Mondialisation, v. 2, 2011. Disponível em: $<$ http://www.cadeul.ulaval.ca/envoi/lenseignement_superieur_a_lhorizon_2030.pdf $>$. Acesso em 15 de fev. de 2019.

PACHECO, José Augusto. Estudos Curriculares, Porto: Portugal: Porto Editora, 2005. 
PACHECO, José Augusto. Educação, Formação e Conhecimento, Porto, Portugal: Porto Editora, 2014.

PACHECO, José Augusto. Currículo: teoria e práxis. Porto, Portugal: Porto Editora, 1996. PERONI, Vera Maris Vidal. As relações entre o público e o privado nas políticas educacionais no contexto da terceira via. Currículo sem fronteiras, v. 13, n.2, p.234-255, maio/ago. 2013.

POPKEWITZ, Thomas. Reconhecendo diferenças e fabricando a desigualdade: ciências da educação, escolarização e abjeção. Educ. Real, Porto Alegre, v.35, n. 3, p. 77-98, set./dez. 2010. Disponível em: http://www.ufrgs.br/edu realidade. Acesso em: 07 de set. De 2019. POPKEWITZ, Thomas. Sistema de pensamento na educação e políticas de inclusão (e exclusão) escolar. Entrevista com Thomaz S. Popkewitz, 2014. Edu. Pesq. São Paulo, v. 42, n. 4 , p. 1151, out./dez. 2016.

RAWOLLE, S. \& LINGADR, B. EI Estado burocrático autoritário. Buenos Aires: Editorial del Belgrano, 2013.

ROBERTSON, Susan; DALE, Roger. The Social Justice Implications of Privatisation in Education Governance Frameworks: A Relational Account. Oxford Review of Education,

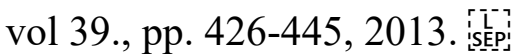

ROBERTSON, Susan; DALE, Roger. Regulação e risco na governança da educação. Gestão dos problemas de legislação e coesão social em educação nos estados competivivos. Educação, Sociedade \& Culuras, n.15, p. 117-147, 2001.

ROBERTSON, Susan; DALE, Roger. Comparando políticas em um mundo em globalização: reflexões metodológicas, Educ. Real, v.42, n. 3, Porto Alegre, 2017. ROBERTSON, Susan \& VERGER, Antoni, A origem das parcerias Público-Privadas na governança global da educação. Educ. Soc., Campinas, 33, n.121, p. 1133-1156, out.-dez. 2012.

SANTOS, Boaventura. de Sousa. Um discurso sobre as ciências. 16. ed. Porto: Edições Afrontamento, 2010. 
SANTOS, Boaventura. de Sousa. O fim do império cognitivo, Coimbra, Portugal: Edições Almedina, 2018.

SANTOS, Boaventura. de Sousa. A Universidade no século XXI: para uma reforma democrática e emancipatória da Universidade. São Paulo: Cortez Editora, 2004.

SACRISTÁN, José Gimeno. O Currículo: uma reflexão sobre a prática. Porto Alegre, RS.: Penso Editora LTDA, 2017.

SANTOMÉ, Jurjo. Torres. Educação em tempo de neoliberalismo. São Paulo: Artmed Editora S.A, 2003.

SIQUEIRA, Ângela. C. A regulamentação do enfoque comercial no setor educacional via OMC/GATS. Revista Brasileira de Educação, Rio de Janeiro, n. 26, p.145-156, maio/ago, 2004.

TEODORO, António. Educação, Globalização e Neoliberalismo: os novos modos de regulação transnacional das políticas de educação. Lisboa, Portugal: Edições Universitárias Lusófonas, 2010.

TEODORO, António. Globalização e Educação: políticas educacionais e novos modos de governança. Porto: Edições Afrontamento, 2003.

TEODORO, António. Políticas Educativas: considerações breves sobre a transdisciplinaridade de um campo de estudo. Revista de Humanidades e Tecnologias n.1, dec.2010. Supl. 1. ISSN 1646-4028. Disponível em:

http://revistas.ulusofona.pt/indez.php/rhumanidades/article/view/1259. Acesso em: 21 out. 2019.

UNESCO, CNE, MEC, SPELLER, P. ROBL, F. MENEGUEL, M.S., Desafios e perspectivas da educação superior brasileira para a próxima década. Brasília, 2012. UNESCO; RAINIER, Nina Beatriz Stocco; ALVES, Angela Limongi Alvarenga (orgs.) Direito à educação e direitos na educação em perspectiva interdisciplinar. São Paulo: Cátedra UNESCO de Direto à Educação/Universidade de São Paulo (USP), 2018. 
YOUNG. Michael F. D. Conhecimento e Currículo: Do socioconstrutivismo ao realismo social na sociologia da educação. Porto, Portugal: Porto Editora, 2010.

VARELA, Bartolomeu Lopes. Concepções, Práxis e Tendências de Desenvolvimento

Curricular no Ensino Superior Público em Cabo Verde: um estudo de caso sobre a Universidade de Cabo Verde. 2011. Tese (Doutoramento em Ciências da Educação Especialidade de Desenvolvimento Curricular) - Universidade do Minho, Braga, 2011. Disponível em: http://hdl.handle.net/1822/19988. Acesso em: 24 ago. 2019.

ZARIFIAM P. Objetivo Competência: por uma nova lógica. 1a. ed. São Paulo: Atlas; 2001.

Submetido em: $13 / 01 / 2020$

Aprovado em: 01/04/2020 